\title{
Cyanobacteria as a platform for biofuel production
}

\author{
Nicole E. Nozzi, John W. K. Oliver and Shota Atsumi *
}

Department of Chemistry, University of California Davis, Davis, CA, USA

\section{Edited by:}

Patrik R. Jones, University of Turku, Finland

Reviewed by:

Ganesh Sriram, University of Maryland, USA

Patrik R. Jones, University of Turku, Finland

\section{*Correspondence.}

Shota Atsumi, Department of

Chemistry, University of California

Davis, One Shields Avenue, Davis, CA

95616, USA

e-mail: atsumi@chem.ucdavis.edu
Cyanobacteria have great potential as a platform for biofuel production because of their fast growth, ability to fix carbon dioxide gas, and their genetic tractability. Furthermore they do not require fermentable sugars or arable land for growth and so competition with cropland would be greatly reduced. In this perspective we discuss the challenges and areas for improvement most pertinent for advancing cyanobacterial fuel production, including: improving genetic parts, carbon fixation, metabolic flux, nutrient requirements on a large scale, and photosynthetic efficiency using natural light.

Keywords: cyanobacteria, biofuel, synthetic biology, metabolic engineering, photosynthesis
On October 31, 2011 world population officially hit seven billion, only 12 years after the six billion mark in 1999. The age of exploration and discovery of untapped land and untouched resources is over, humanity must now learn to cultivate and renew energy sources in the same way that we do for food. The ability of biology to renew and reproduce holds great promise for sustainable fuel production if it can be effectively harnessed. Specifically, photosynthetic life self-replicates the intricate machinery needed for capture and conversion of light energy and waste carbon dioxide. We are already utilizing photosynthesis through the fermentation of farm crops for bioethanol production. However, though this is a renewable source of fuel, it competes with cropland (Witcover et al., 2013). What is needed is biological fuel production that functions orthogonally to food production. The use of plantderived lignocellulose derived from agricultural waste as a source of fermentable sugars is an option favored by many current startup companies. However, this material consists mainly of heavily cross-linked polymers responsible for plant structure and strength, thus the process for breaking down such material to a form that can be readily utilized by bacteria for fermentation is a highly energy intensive process (Sanderson, 2011).

Alternatively, the use of photosynthetic microorganisms as a platform for biological fuel production has gained considerable popularity as an option that could potentially avoid some of the problems aforementioned (Machado and Atsumi, 2012). As photosynthetic microorganisms directly fix carbon dioxide as their primary carbon source, the need for a source of fermentable sugars as a carbon feedstock for biological fuel production could be eliminated. Eukaryotic algae and cyanobacteria have been the primary organisms of interest for this strategy of fuel production. Both can grow much faster than plants and do not need to be grown on arable land (Dismukes et al., 2008). Furthermore, these organisms are grown submerged in water, which allows for the use of $\mathrm{CO}_{2}$ at higher concentrations than that of ambient air (Sheehan et al., 1998) and could potentially allow for the use of concentrated $\mathrm{CO}_{2}$ emissions from waste industrial sources. Research on eukaryotic algae has primarily centered on their ability to produce large amounts of lipids for the production of biodiesel (Pate et al., 2011). However despite years of research, eukaryotic algae have yet to realize their industrial potential and synthetic biology techniques for eukaryotic systems remain elusive limiting our ability to improve and diversify these strains (Radakovits et al., 2010). Cyanobacteria, prokarytic organisms, combine of the advantages of both eukaryotic algae, as a photosynthetic microorganism, and E. coli, as a tractable and naturally transformable host.

Cyanobacteria have already been engineered to produce a number of different biofuel related compounds (Machado and Atsumi, 2012). In one of the first examples of biofuel production in cyanobacteria, Synechococcus elongatus sp. strain PCC 7942 (S. elongatus) was successfully engineered to produce ethanol through the addition of a pyruvate decarboxylase and an alcohol dehydrogenase, redirecting carbon from pyruvate (Deng and Coleman, 1999). Cyanobacterial production of ethanol has since been significantly improved (Dexter and Fu, 2009; Gao et al., 2012). Though compatible with current fuel infrastructure as a supplement to gasoline, ethanol serves as a rather poor gasoline substitute due to its hygroscopicity and low energy density. For these reasons efforts have shifted toward longer carbon chain fuels (Table 1). Isobutyraldehyde, an important chemical feedstock for hydrocarbons normally derived from petroleum, was successfully produced in S. elongatus by diverting carbon flux from the valine biosynthesis pathway through the addition of a ketoacid decarboxylase, reaching $1.1 \mathrm{~g} / \mathrm{L}$ in 8 days (Atsumi et al., 2009). Isobutanol, a promising candidate for a gasoline substitute, can easily be obtained from isobutyraldehyde via chemical conversion. Direct biological production of isobutanol from $S$. elongatus was achieved with the addition of an alcohol dehydrogenase reaching $450 \mathrm{mg} / \mathrm{L}$ in 6 days (Atsumi et al., 2009). Three heterologous enzymes, acetolactate synthase, 2-acetolactate decarboxylase, and a secondary alcohol dehydrogenase, introduced into S. elongatus allowed for the diversion of carbon flux from pyruvate to the production of the chemical feedstock 2,3-butanediol reaching $2.4 \mathrm{~g} / \mathrm{L}$ in 21 days (Oliver et al., 2013). Other chemicals produced with heterologous biosynthetic pathways from cyanobacteria include 1-butanol 
Table 1 | Titers for various biochemicals.

\begin{tabular}{|c|c|c|c|}
\hline Compound & Organism & Titer & Reference \\
\hline Acetone & $\begin{array}{l}\text { Synechocystis sp. } \\
\text { PCC6803 }\end{array}$ & $36 \mathrm{mg} / \mathrm{L}$ & $\begin{array}{l}\text { Zhou et al. } \\
\text { (2012) }\end{array}$ \\
\hline 2,3-Butanediol & $\begin{array}{l}\text { S. elongatus sp. } \\
\text { PCC } 7942\end{array}$ & $2.4 \mathrm{~g} / \mathrm{L}$ & $\begin{array}{l}\text { Oliver et al. } \\
\text { (2013) }\end{array}$ \\
\hline 1-Butanol & $\begin{array}{l}\text { S. elongatus sp. } \\
\text { PCC } 7942\end{array}$ & $30 \mathrm{mg} / \mathrm{L}$ & $\begin{array}{l}\text { Lan and } \\
\text { Liao (2012) }\end{array}$ \\
\hline Ethanol & $\begin{array}{l}\text { Synechocystis sp. } \\
\text { PCC6803 }\end{array}$ & $5.5 \mathrm{~g} / \mathrm{L}$ & $\begin{array}{l}\text { Gao et al. } \\
(2012)\end{array}$ \\
\hline Ethylene & $\begin{array}{l}\text { Synechocystis sp. } \\
\text { PCC6803 }\end{array}$ & $171 \mathrm{mg} / \mathrm{L} \cdot \mathrm{day}$ & $\begin{array}{l}\text { Ungerer } \\
\text { et al. (2012) }\end{array}$ \\
\hline Fatty acids & $\begin{array}{l}\text { Synechocystis sp. } \\
\text { PCC6803 }\end{array}$ & $197 \mathrm{mg} / \mathrm{L}$ & $\begin{array}{l}\text { Liu et al. } \\
\text { (2011) }\end{array}$ \\
\hline Isobutanol & $\begin{array}{l}\text { S. elongatus sp. } \\
\text { PCC } 7942\end{array}$ & $450 \mathrm{mg} / \mathrm{L}$ & $\begin{array}{l}\text { Atsumi } \\
\text { et al. (2009) }\end{array}$ \\
\hline Isobutyraldehyde & $\begin{array}{l}\text { S. elongatus sp. } \\
\text { PCC7942 }\end{array}$ & $1.1 \mathrm{~g} / \mathrm{L}$ & $\begin{array}{l}\text { Atsumi } \\
\text { et al. (2009) }\end{array}$ \\
\hline Isoprene & $\begin{array}{l}\text { Synechocystis sp. } \\
\text { PCC6803 }\end{array}$ & $\begin{array}{l}50 \mu \mathrm{g} / \mathrm{g} \text { dry } \\
\text { cell.day }\end{array}$ & $\begin{array}{l}\text { Lindberg } \\
\text { et al. (2010) }\end{array}$ \\
\hline 2-Methyl-1-butanol & $\begin{array}{l}\text { S. elongatus sp. } \\
\text { PCC7942 }\end{array}$ & $200 \mathrm{mg} / \mathrm{L}$ & $\begin{array}{l}\text { Shen and } \\
\text { Liao (2012) }\end{array}$ \\
\hline
\end{tabular}

(29.9 mg/L) (Lan and Liao, 2012), 2-methyl-1-butanol (200 mg/L) (Shen and Liao, 2012), acetone (36 mg/L) (Zhou et al., 2012), ethylene ( $171 \mathrm{mg} / \mathrm{L} \cdot$ day) (Takahama et al., 2003; Ungerer et al., 2012), isoprene $(0.05 \mathrm{mg} / \mathrm{g}$ dry cell. day) (Lindberg et al., 2010), and fatty acids (197 mg/L) (Liu et al., 2011).

These successes clearly demonstrate the malleability of cyanobacteria as a chemical production platform. Over the past 15 years we have moved from detection of the first industrial chemicals produced from exogenous genes in cyanobacteria, through a burst of discovery and experimentation with pathways and design in photosynthetic prokaryotes, to our current status of balancing and matching of production to the metabolism of the host (Oliver et al., 2013). In this perspective we seek to highlight the greatest challenges that must be overcome before sustainable biofuel production in cyanobacteria can be fully realized. We will focus mainly on pathway engineering and strain development (Figure 1). Though we will touch on it, the challenges concerning large scale commercialization are largely beyond the scope of this work.

\section{IMPROVING GENETIC PARTS FOR CYANOBACTERIA}

Most engineered pathways in cyanobacteria utilize gene expression systems derived from E. coli (Atsumi et al., 2009; Shen and Liao, 2012), however it is known that gene expression in E. coli cannot accurately predict gene expression in a photosynthetic host (Huang et al., 2010; Oliver et al., 2013). Many engineered systems have employed endogenous cyanobacterial promoters for constitutive expression (Deng and Coleman, 1999), but few such genetic parts have been specifically characterized for utility in metabolic engineering (Heidorn et al., 2011).

The cyanobacterial RNA polymerase (RNAP) holoenzyme contains different subunits than those found in the RNAPs of

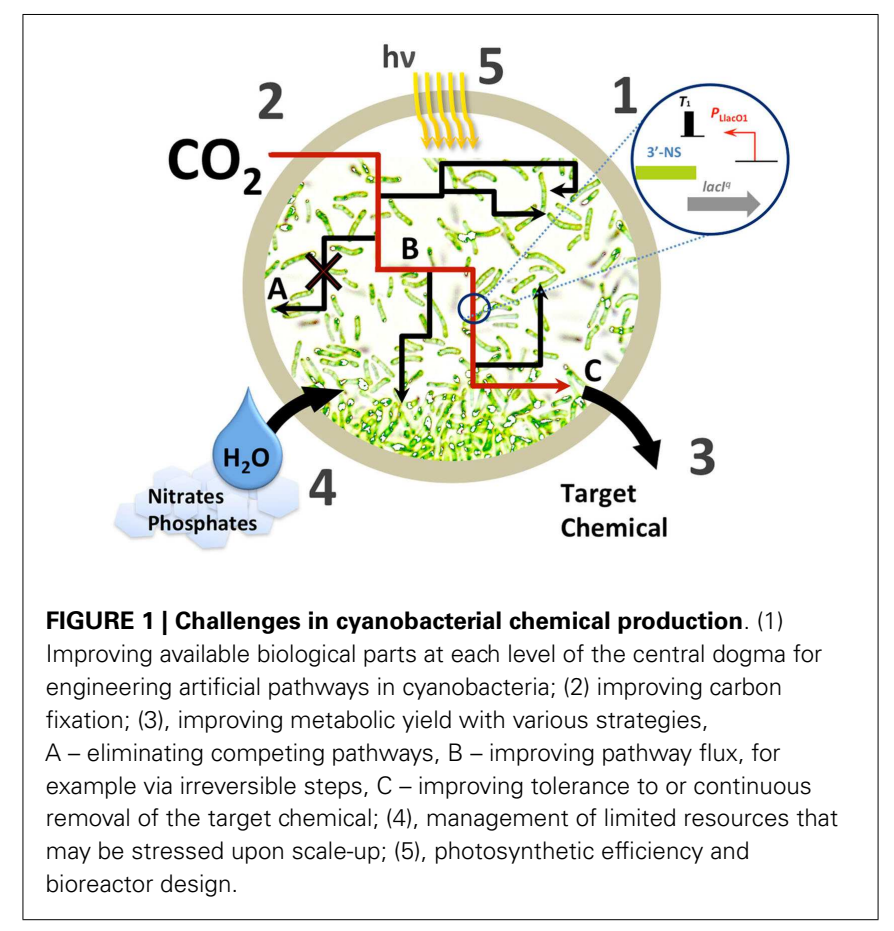

most bacteria. Furthermore, though cyanobacteria contain $\sigma$ factors belonging to the $\sigma^{70}$ family which are also found in $E$. coli, they do not possess any $\sigma^{54}$ family $\sigma$ factors which are found in most bacteria (Imamura and Asayama, 2009). With these differences in mind, the discovery that many promoter sequences commonly employed in E. coli engineering, such as the lac inducible expression system, do not function well or at all in cyanobacterial systems may not come as a great surprise (Huang et al., 2010; Oliver et al., 2013). Characterization of endogenous cyanobacterial promoters constitutes a short list including light-inducible and metal-inducible promoters (Heidorn et al., 2011). At the translational level, an analysis of ribosomal binding site (RBS) sequences of all genes in Synechocystis 6803 revealed that only $26 \%$ contained the RBS core sequence compared to $57 \%$ in E. coli (Ma et al., 2002). Indeed, a comparison of the strength of an RBS sequence modeled after those identified in Synechocystis 6803 and three BioBrick sequences further revealed the importance of choosing biological parts adapted specifically for the organism of interest, cyanobacteria in this case (Heidorn et al., 2011). The differences in both transcriptional and translational regulation systems in cyanobacteria must be accounted for if biological parts from E. coli are utilized in engineering designs.

Experiments have indicated the operation of anti-sense RNA in regulating gene expression in cyanobacterial systems (Georg and Hess, 2011). Indeed anti-sense suppression has been successfully used in S. elongatus to regulate gene expression (Holtman et al., 2005; Cai et al., 2013). Evidence of the CRISPR-Cas system, which has recently become a topic of intense interest, has been identified in most cyanobacterial strains (Cai et al., 2013). The great potential of the CRISPR-Cas system as an engineering tool has already been demonstrated in E. coli (Qi et al., 2013). 


\section{IMPROVING $\mathrm{CO}_{2}$ FIXATION}

Despite billions of years of evolution, nature's ability to effectively sequester $\mathrm{CO}_{2}$ would seem on the surface to be strangely inefficient. Ribulose-1,5-bisphosphate carboxylase/oxygenase ( $\mathrm{RuBisCO}$ ), the enzyme responsible for $\mathrm{CO}_{2}$ fixation, appears to be lacking in the two qualities enzymes are most known for: high catalytic rate and high specificity (Tcherkez et al., 2006). RuBisCO's lack of specificity lies in its inherent tendency to bind $\mathrm{O}_{2}$ instead of $\mathrm{CO}_{2}$, which results in a futile use of energy. Attempts to improve this specificity via site-directed mutagenesis have found that improved specificity always comes at the expense of catalytic rate (Tcherkez et al., 2006; Ninomiya et al., 2008). Consequently, RuBisCO may already be perfectly optimized to the best possible compromise between specificity and catalytic efficiency. Among photosynthetic organisms, cyanobacteria have already evolved very efficient carbon concentrating mechanisms (CCM) which allow RuBisCO to operate near $V_{\max }$ by lowering the need for high specificity (Savir et al., 2010; Price, 2011).

However, there are large differences between the conditions under which RuBisCO evolved and laboratory or bioreactor conditions which can provide high intensity light and concentrated $\mathrm{CO}_{2}$. These artificial conditions may allow for some improvement of carbon fixation. For example, expression of heterologous RuBisCO resulted in a twofold increase in isobutyraldehyde production in S. elongatus, indicating a possible increase in carbon fixation (Atsumi et al., 2009). However, the localization of heterologous RuBisCO to the cytosol and not the carboxysome (Iwaki et al., 2006) makes it unclear which limitation is alleviated. Even if we evolve organisms to match saturated $\mathrm{CO}_{2}$ conditions, we will still be limited by photosystem II electron turnover after less than a threefold increase in RuBisCO activity (Iwaki et al., 2006).

\section{IMPROVING METABOLIC YIELD}

Titers for cyanobacterial production of bulk products such as chemical feedstocks, remain significantly lower than fermentative systems (Table 1) (Lan and Liao, 2013). Initial studies reported barely detectable production of chemicals from exogenous pathways (Deng and Coleman, 1999; Lindberg et al., 2010; Lan and Liao, 2011). This has improved rapidly along with host specific design techniques (Atsumi et al., 2009; Ungerer et al., 2012; Oliver et al., 2013). Historically the improvement of exogenous chemical production has followed characterization of the organism. In E. coli, arguably the most well characterized model organism available, yields increased steadily along with genetic technology and have started approaching theoretical yields only recently (Inokuma et al., 2010; Shen et al., 2011). E. coli still finds little application in industrial settings, due to complications in scale-up (Huffer et al., 2012). Cyanobacteria, while often stated as having a wealth of information available compared to eukaryotic algae, are comparatively uncharacterized for metabolic engineering as compared to fermentative systems (see Improving Genetic Parts for Cyanobacteria). Even on the scale of basic metabolism, a missing gene to complete the TCA cycle in cyanobacteria was only recently characterized (Zhang and Bryant, 2011).

General strategies for metabolic optimization can be grouped into three areas: elimination of competing pathways, maximizing pathway flux, and improving tolerance to or separating out toxic products (with gas stripping for example). Specific to photosynthetic organisms, a fourth strategy can be added to this list: improving carbon uptake, which we discuss in Section "Improving $\mathrm{CO}_{2}$ Fixation." The elimination of competing pathways in cyanobacteria is almost uncharted. Some effort has been put into testing the removal of glycogen pathways (Suzuki et al., 2010), and libraries of knockouts have been constructed (Holtman et al., 2005), however investigations in production optimization similar to those in E. coli (Rodriguez and Atsumi, 2012) are hindered by the lack of a strong, standardized chemical production system in cyanobacteria to serve as a benchmark for improvement. In contrast to the strategy of eliminating competing pathways, most work in cyanobacteria has focused on improving pathway flux. For example, production of 2,3-butanediol appears to redirect up to $60 \%$ of biomass toward product through the use of irreversible steps, and enzyme screening (Oliver et al., 2013). In the future, computational modeling could be applied to cyanobacteria as it has been to other organisms for the identification of distant pathways that could potentially affect pathway flux, for example in terms of cofactor or ATP availability (Asadollahi et al., 2009; Agren et al., 2013; Misra et al., 2013).

By nature cyanobacteria brings with it an oxygenic atmosphere. This fact automatically limits the list of potential heterologous enzymes available for pathway construction. Many enzymes have displayed lowered activity when transferred into cyanobacteria and have clearly limited production (Lan and Liao, 2012; Ungerer et al., 2012). Changing enzymes in these cases greatly improved yield. Cofactor matching, choosing enzymes that can utilize NADPH versus NADH, is also important when working in a photosynthetic context (Lan and Liao, 2012). Currently pathways exist that appear not to be limited by pathway flux (Oliver et al., 2013), allowing for greater characterization of other limitations in metabolism. Improving tolerance to products should in theory allow for higher titers in culture media (Atsumi et al., 2010), however no investigations into improving cyanobacterial resistance to toxicity have been conducted. Alternatively constant removal of toxic products can increase production (Atsumi et al., 2009; Inokuma et al., 2010; Ungerer et al., 2012), although the feasibility of such processes on an industrial scale remains to be proven.

For continuous production from cyanobacterial strains, culture stability remains a challenge with peak titers occurring after a week in many cases. Loss of production may be due to genetic instability, as carbon diversion creates a selective pressure for spontaneous mutants with an inactive pathway. Production durations have been increased in studies that included codon optimization of key genes to eliminate mutation hotspots, or lowering of end-product toxicity to increase viability of production strains, however more data is needed to clearly define the factors impacting duration (Ungerer et al., 2012; Oliver et al., 2013).

\section{MANAGING INPUTS: NUTRIENT AND WATER REOUIREMENTS}

Though cyanobacteria do not compete with food crops in terms of land, there is some concern that competition for nutrients may become an issue. Cyanobacteria require a source of nitrogen and phosphorous just as plants do, and fertilizer production for plant growth is already a huge industry. Large scale culturing of 
cyanobacteria with similar nutrient requirements could put significant strain on these resources. A study of potential resource impacts for algae scale-up noted that target production greater than 10 billion gallons per year would require nutrient inputs that could double current fertilizer use (Pate et al., 2011). Current production strains could be expected to give similar nutrient requirement projections.

Phosphate for fertilizer use is sourced entirely from the mining of limited resources. While projections conflict on exactly when these mines will be exhausted, the limitation is clear. We must consider nutrient recovery from domestic wastewater and agricultural runoff. Both biological and chemical methods are being considered for phosphate recovery and recycling. Enhanced biological phosphorous removal (EBPR) utilizes polyphosphate accumulating organisms (PAOs), primarily microorganisms belonging to the Accumulibacter group (Yuan et al., 2012). Chemical methods include: chemically reactive filters, enhancing natural struvite (magnesium ammonium phosphate) precipitation, nanomaterials, and polymers with high phosphorous affinity (Pratt et al., 2012). While much work is underway concerning the removal of phosphorous from wastewater, the challenge lies in the recovery of the phosphorous in a way that does not carry along heavy metals and pathogens.

Electricity can be used to generate nitrogen in the Haber-Bosch process, however the bioavailable nitrogen generated in this way is not recycled and can end up as nitrous oxide greenhouse gases. To mitigate this problem renewable strategies for algal recycling of nitrogen have been proposed (Huo et al., 2012). Cyanobacteria capable of efficiently fixing nitrogen from air are known, and possibilities for engineering these strains as production systems remain to be explored (Golden et al., 1985; Steinberg and Meeks, 1991). Large scale cyanobacterial production would also require enormous amounts of water. Current metabolic engineering for chemical production has mainly focused on freshwater strains. To avoid competition with drinking water, large scale production must adapt to strains that can grow and produce competitively in wastewater or salt water. Genetic tools for salt-water strains are available (Frigaard et al., 2004), although no specific exogenous chemical production has been investigated. Work is progressing in the application of eukaryotic algae to wastewater treatment (Cabanelas et al., 2013; Hu et al., 2013), similar work should be applied also to engineered cyanobacteria.

\section{PHOTOSYNTHETIC EFFICIENCY AND BIOREACTORS}

The simple nutrient requirements of cyanobacteria (mainly light, water, and $\mathrm{CO}_{2}$ ) make it an ideal candidate for biofuel production, but the requirement of light exposure makes the design of an industrial bioreactor challenging. To achieve maximum photosynthetic efficiency light must be provided to cells in saturating amounts (Iwaki et al., 2006). Self-shading prevents this

\section{REFERENCES}

Agren, R., Otero, J. M., and Nielsen, J. (2013). Genome-scale modeling enables metabolic engineering of Saccharomyces cerevisiae for succinic acid production. J. Ind. Microbiol. Biotechnol. 40, 735-747. doi:10. 1007/s10295-013-1269-3
Asadollahi, M. A., Maury, J., Patil, K. R., Schalk, M., Clark, A., and Nielsen, J. (2009). Enhancing sesquiterpene production in Saccharomyces cerevisiae through in silico driven metabolic engineering. Metab. Eng. 11, 328-334. doi:10.1016/j.ymben.2009.07.001

from being possible if the culture depth is more than a few inches, and success is highly dependent on the rate of cell mixing (Qiang et al., 1998). Because economy of scale implies longer path lengths (such as raceway ponds) and natural irradiance, industrial outlooks have focused on light as the limiting factor in production calculations. It appears that only $10-15 \%$ of sunlight will be available to cells for photosynthesis after non-active radiation, and losses from events such as reflection are subtracted (Robertson et al., 2011). Because of this, maximum production rates measured in high $\mathrm{CO}_{2}$ and high light conditions, in particular in strains with improved $\mathrm{CO}_{2}$ fixation may not be applicable to large scale systems. New bioreactor designs and production strain designs need to find a balance between capturing all of the available sunlight and using the smallest volume possible to reduce the cost of purification.

The large amount of sunlight incident on cells but not available for photosynthesis is capable of creating heat in cultures. Both this and ambient temperatures may impair production in high insolation areas. The engineering of hyperthermophilic bacteria, capable of tolerating up to $70^{\circ} \mathrm{C}$, could alleviate this problem (Onai et al., 2004). Another approach is to convert non-photosynthetically active radiation into usable wavelengths (Wondraczek et al., 2013) to prevent heat absorption.

Industrial systems relying on the natural irradiation of sunlight are limited to a diurnal cycle. In 2013 the successful insertion of sugar transporter systems into $S$. elongatus made it possible for this cyanobacterium to grow in the absence of light (McEwen et al., 2013). This development opens the door to the possibility of 24 hour chemical production by mediating the cost that would be required to electrically illuminate large scale cultures. Cyanobacterial strains that are natural photoheterotrophs such as Synechocystis sp. PCC 6803 could also be used for this purpose.

\section{FINAL THOUGHTS}

Seen as a list together the challenges to be conquered before cyanobacterial biofuel production can be realized on an industrial scale can seem great. However, taking a step back, the benefits such a renewable system could reap far outweigh the investment necessary to achieve its reality. Significant progress has already been made in each challenge area since interest in cyanobacteria was sparked. The greatest potential to be unlocked lies in the characterization of tightly controlled expression systems tailored for cyanobacteria. Until we can engineer cyanobacteria in a predictable manner, all other concerns, such as those related to scaleup, must wait. "Plug-and-play" biological parts must be adapted to the host of interest. Too long have we been trying to run software designed for a different operating system. Once we are speaking the same language, engineering designs for cyanobacterial systems will balloon with possibilities.

Atsumi, S., Higashide, W., and Liao, J. C. (2009). Direct photosynthetic recycling of carbon dioxide to isobutyraldehyde. Nat. Biotechnol. 27, 1177-1180. doi:10.1038/nbt.1586

Atsumi, S., Wu, T. Y., Machado, I. M. P., Huang, W. C., Chen, P. Y., Pellegrini, M., et al. (2010).
Evolution, genomic analysis and reconstruction of isobutanol tolerance in Escherichia coli. Mol. Syst. Biol. 6, 449. doi:10.1038/msb.2010.98

Cabanelas, I. T., Ruiz, J., Arbib, Z., Chinalia, F. A., Garrido-Perez, C., Rogalla, F., et al. (2013). Comparing 
the use of different domestic wastewaters for coupling microalgal production and nutrient removal. Bioresour. Technol. 131, 429-436. doi:10. 1016/j.biortech.2012.12.152

Cai, F., Axen, S. D., and Kerfeld, C. A. (2013). Evidence for the widespread distribution of CRISPR-Cas system in the phylum cyanobacteria. RNA Biol. 10, 687-693. doi:10.4161/rna. 24571

Deng, M.-D., and Coleman, J. R. (1999). Ethanol synthesis by genetic engineering in cyanobacteria. Appl. Environ. Microbiol. 65, 523-528.

Dexter, J., and Fu, P. (2009). Metabolic engineering of cyanobacteria for ethanol production. Energy Environ. Sci. 2, 857. doi:10.1039/b811937f

Dismukes, G. C., Carrieri, D., Bennette, N., Ananyev, G. M., and Posewitz, M. C. (2008). Aquatic phototrophs: efficient alternatives to land-based crops for biofuels. Curr. Opin. Biotechnol. 19, 235-240. doi: 10.1016/j.copbio.2008.05.007

Frigaard, N.-U., Sakuragi, Y., and Bryant, D. (2004). "Gene inactivation in the cyanobacterium Synechococcus sp. PCC 7002 and the green sulfur bacterium Chlorobium tepidum using in vitro-made DNA constructs and natural transformation," in Photosynthesis Research Protocols, ed. R. Carpentier (Totowa: Humana Press), 325-340.

Gao, Z. X., Zhao, H., Li, Z. M., Tan, X. M., and Lu, X. F. (2012). Photosynthetic production of ethanol from carbon dioxide in genetically engineered cyanobacteria. Energy Environ. Sci. 5, 9857-9865. doi:10.1038/ nbt. 1586

Georg, J., and Hess, W. R. (2011). cis-Antisense RNA, another level of gene regulation in bacteria. Microbiol. Mol. Biol. Rev. 75, 286-300. doi:10.1128/MMBR.00032-10

Golden, J. W., Robinson, S. J., and Haselkorn, R. (1985). Rearrangement of nitrogen fixation genes during heterocyst differentiation in the cyanobacterium Anabaena. Nature 314, 419-423. doi:10.1038/314419a0

Heidorn, T., Camsund, D., Huang, H. H., Lindberg, P., Oliveira, P., Stensjo, K., et al. (2011). Synthetic biology in cyanobacteria engineering and analyzing novel functions. Meth. Enzymol. 497, 539-579. doi:10.1016/ B978-0-12-385075-1.00024-X

Holtman, C. K., Chen, Y., Sandoval, P., Gonzales, A., Nalty, M. S., Thomas, T. L., et al. (2005). Highthroughput functional analysis of the Synechococcus elongatus PCC 7942 genome. DNA Res. 12, 103-115. doi:10.1093/dnares/12.2.103
Hu, B., Zhou, W., Min, M., Du, Z., Chen, P., Ma, X., et al. (2013). Development of an effective acidogenically digested swine manure-based algal system for improved wastewater treatment and biofuel and feed production. Appl. Energy 107, 255-263. doi:10.1016/j.apenergy.2013.02.033

Huang, H. H., Camsund, D., Lindblad, P., and Heidorn, T. (2010). Design and characterization of molecular tools for a Synthetic Biology approach towards developing cyanobacterial biotechnology. Nucleic Acids Res. 38, 2577-2593. doi:10.1093/nar/gkq164

Huffer, S., Roche, C. M., Blanch, H. W., and Clark, D. S. (2012). Escherichia coli for biofuel production: bridging the gap from promise to practice. Trends Biotechnol. 30, 538-545. doi:10.1016/j.tibtech.2012.07.002

Huo, Y.-X., Wernick, D. G., and Liao, J. C. (2012). Toward nitrogen neutral biofuel production. Curr. Opin. Biotechnol. 23, 406-413.

Imamura, S., and Asayama, M. (2009). Sigma factors for cyanobacterial transcription. Gene Regul. Syst Biol. 3, 65-87.

Inokuma, K., Liao, J. C., Okamoto, M., and Hanai, T. (2010). Improvement of isopropanol production by metabolically engineered Escherichia coli using gas stripping. J. Biosci. Bioeng. 110, 696-701. doi:10.1016/j.jbiosc. 2010.07.010

Iwaki, T., Haranoh, K., Inoue, N., Kojima, K., Satoh, R., Nishino, T., et al. (2006). Expression of foreign type I ribulose-1,5bisphosphate carboxylase/oxygenase (EC 4.1.1.39) stimulates photosynthesis in cyanobacterium Synechococcus PCC7942 cells. Photosyn. Res. 88, 287-297. doi:10.1007/s11120-006-9048-x

Lan, E. I., and Liao, J. C. (2011). Metabolic engineering of cyanobacteria for 1-butanol production from carbon dioxide. Metab. Eng. 13, 353-363. doi:10.1016/j.ymben. 2011.04 .004

Lan, E. I., and Liao, J. C. (2012). ATP drives direct photosynthetic production of 1-butanol in cyanobacteria. Proc. Natl. Acad. Sci. U.S.A. 109, 6018-6023. doi:10.1073/pnas. 1200074109

Lan, E. I., and Liao, J. C. (2013). Microbial synthesis of n-butanol, isobutanol, and other higher alcohols from diverse resources. Bioresour. Technol. 135, 339-349. doi:10.1016/ j.biortech.2012.09.104

Lindberg, P., Park, S., and Melis, A. (2010). Engineering a platform for photosynthetic isoprene production in cyanobacteria, using Synechocystis as the model organism. Metab. Eng. 12, 70-79. doi:10.1016/ j.ymben.2009.10.001

Liu, X., Sheng, J., and Curtiss, R. III (2011). Fatty acid production in genetically modified cyanobacteria. Proc. Natl. Acad. Sci. U.S.A. 108, 6899-6904. doi:10.1073/pnas. 1103014108

Ma, J., Campbell, A., and Karlin, S. (2002). Correlations between ShineDalgarno sequences and gene features such as predicted expression levels and operon structures. J. Bacteriol. 184, 5733-5745. doi:10.1128/ JB.184.20.5733-5745.2002

Machado, I. M., and Atsumi, S. (2012). Cyanobacterial biofuel production. J. Biotechnol. 162, 50-56. doi:10. 1016/j.jbiotec.2012.03.005

McEwen, J. T., Machado, I. M. P., Connor, M. R., and Atsumi, S. (2013). Engineering Synechococcus elongatus PCC 7942 for continuous growth under diurnal conditions. Appl. Environ. Microbiol. 79, 1668-1675. doi: 10.1128/AEM.03326-12

Misra, A., Conway, M. F., Johnnie, J., Qureshi, T. M., Derrick, A. M., Agbo, E. C., et al. (2013). Metabolic analyses elucidate nontrivial gene targets for amplifying dihydroartemisinic acid production in yeast. Front. Microbiol. 4:200. doi:10. 3389/fmicb. 2013.00200

Ninomiya, N., Ashida, H., and Yokota, A. (2008). "Improvement of cyanobacterial Rubisco by introducing the latch structure involved in high affinity for $\mathrm{CO}_{2}$ in red algal Rubisco," in Photosynthesis, Energy from the Sun, eds J. Allen, E. Gantt, J. Golbeck, and B. Osmond (Dordrecht: Springer), 868-870.

Oliver, J. W. K., Machado, I. M. P., Yoneda, H., and Atsumi, S. (2013). Cyanobacterial conversion of carbon dioxide to 2,3butanediol. Proc. Natl. Acad. Sci. U.S.A. 110, 1249-1254. doi:10.1073/pnas.1213024110

Onai, K., Morishita, M., Kaneko, T., Tabata, S., and Ishiura, M. (2004). Natural transformation of the thermophilic cyanobacterium Thermosynechococcus elongatus BP1: a simple and efficient method for gene transfer. Mol. Genet. Genomics 271, 50-59. doi:10.1007/ s00438-003-0953-9

Pate, R., Klise, G., and Wu, B. (2011). Resource demand implications for US algae biofuels production scaleup. Appl. Energy 88, 3377-3388. doi: 10.1016/j.apenergy.2011.04.023

Pratt, C., Parsons, S. A., Soares, A., and Martin, B. D. (2012). Biologically and chemically mediated adsorption and precipitation of phosphorus from wastewater. Curr. Opin. Biotechnol. 23, 890-896. doi:10. 1016/j.copbio.2012.07.003

Price, G. D. (2011). Inorganic carbon transporters of the cyanobacterial $\mathrm{CO}_{2}$ concentrating mechanism. Photosyn. Res. 109, 47-57. doi:10. 1007/s11120-010-9608-y

Qi, L. S., Larson, M. H., Gilbert, L. A., Doudna, J. A., Weissman, J. S., Arkin, A. P., et al. (2013). Repurposing CRISPR as an RNA-guided platform for sequence-specific control of gene expression. Cell 152, 1173-1183. doi: 10.1016/j.cell.2013.02.022

Qiang, H., Zarmi, Y., and Richmond, A. (1998). Combined effects of light intensity, light-path and culture density on output rate of Spirulina platensis (Cyanobacteria). Eur. J. Phycol. 33, 165-171. doi:10.1080/ 09670269810001736663

Radakovits, R., Jinkerson, R. E., Darzins, A., and Posewitz, M. C. (2010). Genetic engineering of algae for enhanced biofuel production. Eukaryotic Cell 9, 486-501. doi:10.1128/EC.00364-09

Robertson, D. E., Jacobson, S. A., Morgan, F., Berry, D., Church, G. M., and Afeyan, N. B. (2011). A new dawn for industrial photosynthesis. Photosyn. Res. 107, 269-277. doi:10.1007/ s11120-011-9631-7

Rodriguez, G. M., and Atsumi, S. (2012). Isobutyraldehyde production from Escherichia coli by removing aldehyde reductase activity. Microb. Cell Fact. 11, 90. doi:10.1186/1475-285911-90

Sanderson, K. (2011). Lignocellulose: a chewy problem. Nature 474, S12-S14. doi:10.1038/474S012a

Savir, Y., Noor, E., Milo, R., and Tlusty, T. (2010). Cross-species analysis traces adaptation of Rubisco toward optimality in a low-dimensional landscape. Proc. Natl. Acad. Sci. U.S.A. 107, 3475-3480. doi:10.1073/pnas. 0911663107

Sheehan, J., Dunahay, T., Benemann, J., and Reossler, P. (1998). A Look Back at the U.S. Department of Energy's Aquatic Species Program Biodiesel from Algae. Golden, CO: U.S. Department of Energy, National Renewable Energy Laboratory.

Shen, C. R., Lan, E. I., Dekishima, Y., Baez, A., Cho, K. M., and Liao, J. C. (2011). Driving forces enable high-titer anaerobic 1-butanol synthesis in Escherichia coli. Appl. Environ. Microbiol. 77, 2905-2915. doi: 10.1128/AEM.03034- 10

Shen, C. R., and Liao, J. C. (2012). Photosynthetic production of 
2-methyl-1-butanol from $\mathrm{CO}_{2}$ in cyanobacterium Synechococcus elongatus PCC7942 and characterization of the native acetohydroxyacid synthase. Energy Environ. Sci. 5, 9574-9583. doi:10.1039/c2ee23148d

Steinberg, N. A., and Meeks, J. C. (1991). Physiological sources of reductant for nitrogen fixation activity in Nostoc sp. strain UCD 7801 in symbiotic association with Anthoceros punctatus. J. Bacteriol. 173, 7324-7329.

Suzuki, E., Ohkawa, H., Moriya, K., Matsubara, T., Nagaike, Y., Iwasaki, I., et al. (2010). Carbohydrate metabolism in mutants of the cyanobacterium Synechococcus elongatus PCC 7942 defective in glycogen synthesis. Appl. Environ. Microbiol. 76, 3153-3159. doi:10.1128/AEM. 00397-08

Takahama, K., Matsuoka, M., Nagahama, K., and Ogawa, T. (2003). Construction and analysis of a recombinant cyanobacterium expressing a chromosomally inserted gene for an ethyleneforming enzyme at the $p s b A I$ locus. J. Biosci. Bioeng. 95, 302-305. doi:10.1263/jbb.95.302

Tcherkez, G. G. B., Farquhar, G. D., and Andrews, T. J. (2006). Despite slow catalysis and confused substrate specificity, all ribulose bisphosphate carboxylases may be nearly perfectly optimized. Proc. Natl. Acad. Sci. U.S.A. 103, 7246-7251. doi:10. 1073/pnas.0600605103

Ungerer, J., Tao, L., Davis, M., Ghirardi, M., Maness, P.-C., and Yu, J. (2012). Sustained photosynthetic conversion of $\mathrm{CO}_{2}$ to ethylene in recombinant cyanobacterium Synechocystis 6803. Energy Environ. Sci. 5, 8998. doi:10.1039/c2ee22555g

Witcover, J., Yeh, S., and Sperling, D. (2013). Policy options to address global land use change from biofuels. Energy Policy 56, 63-74. doi:10. 1016/j.enpol.2012.08.030

Wondraczek, L., Batentschuk, M., Schmidt, M. A., Borchardt, R., Scheiner, S., Seemann, B., et al.
(2013). Solar spectral conversion for improving the photosynthetic activity in algae reactors. Nat. Commun. 4, 2047. doi:10.1038/ncomms3047

Yuan, Z., Pratt, S., and Batstone, D. J. (2012). Phosphorus recovery from wastewater through microbial processes. Curr. Opin. Biotechnol. 23 , 878-883. doi:10.1016/j.copbio.2012. 08.001

Zhang, S., and Bryant, D. A. (2011). The tricarboxylic acid cycle in cyanobacteria. Science 334, 1551-1553. doi: 10.1126/science. 1210858

Zhou, J., Zhang, H., Zhang, Y., Li, Y., and Ma, Y. (2012). Designing and creating a modularized synthetic pathway in cyanobacterium Synechocystis enables production of acetone from carbon dioxide. Metab. Eng. 14, 394-400. doi:10.1016/j.ymben. 2012.03.005

Conflict of Interest Statement: The authors declare that the research was conducted in the absence of any commercial or financial relationships that could be construed as a potential conflict of interest.

Received: 04 July 2013; accepted: 12 September 2013; published online: 26 September 2013.

Citation: Nozzi NE, Oliver JWK and Atsumi S (2013) Cyanobacteria as a platform for biofuel production. Front. Bioeng. Biotechnol. 1:7. doi: 10.3389/fbioe.2013.00007

This article was submitted to Synthetic Biology, a section of the journal Frontiers in Bioengineering and Biotechnology. Copyright (C) 2013 Nozzi, Oliver and Atsumi. This is an open-access article distributed under the terms of the Creative Commons Attribution License (CC BY). The use, distribution or reproduction in other forums is permitted, provided the original author(s) or licensor are credited and that the original publication in this journal is cited, in accordance with accepted academic practice. No use, distribution or reproduction is permitted which does not comply with these terms. 